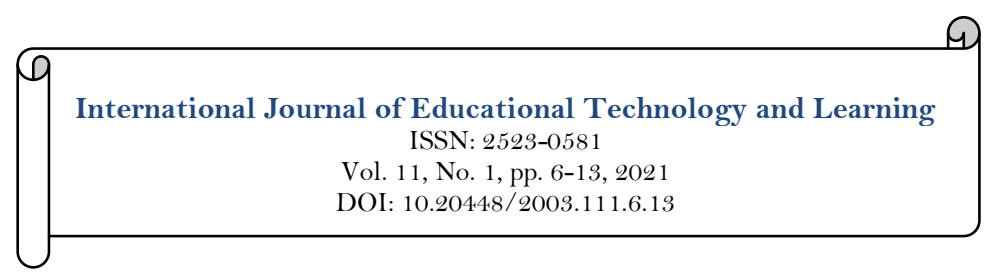

\title{
Teachers' Perceptions of Using Digital Gaming in Classrooms
}

\author{
Rania Kokandy \\ Northern Illinois University, USA. \\ Email:rakokandy@hotmail.com
}

\begin{tabular}{l|l}
\multicolumn{3}{c}{ Abstract } & \\
Digital gaming is a widespread activity in our society; more than 45 million & Keywords: \\
homes have video-game consoles. Mostly, educators see this as a waste of & Intrinsic motivation \\
valuable time that could be used for learning instead. Thus, the purpose of & Extrinsic motivation \\
this qualitative study is to understand teachers' perspectives on using digital & Flow \\
gaming among their students at Northern Illinois University in the state of & Game-based learning. \\
Illinois. The main findings of this study discovered that most of the teachers & Licensed: \\
who were interviewed have a positive attitude toward digital gaming and & This work islicensed under a \\
they think it that has a number of benefits that should not be ignored. & Creative Commons Attribution 4.O \\
Moreover, the results of this study revealed that teachers noted that using & License. \\
digital games increased students' engagement as well as improved students' & Publisher: \\
skills, such as critical thinking, self- directed learning, technological skills, & Scientific Publishing Institute \\
and self- motivation. This study has showed that indeed digital games have & Received: 26 August 2021 \\
a bright future as a tool used at various stages of learning for different levels & Revised: 8 October 2021 \\
of students. Consequently, the educational policy makers should to embrace & Accepted: 28 October 2021 \\
digital gaming as a learning tool. & Published: 17 November 2021
\end{tabular}

Funding: This study received no specific financial support.

Competing Interests: The author declares that there are no conflicts of interests regarding the publication of this paper.

\section{Introduction}

The 21 st century has often been referred to as the age of technology. Technology has changed the way we live, think, and interact with others in our environment. The emergence of new technologies such as "digital gaming" led educators to understand and to find meaningful ways to integrate these technologies into the classroom. Digital Gaming is prevalent in the lives of American teens. Current findings by the Pew Internet \& American Life Project showed that $97 \%$ of youngsters whose ages ranged from 12-17 play digital games, whether on computers, on consoles, or hand-held gadget-devices (Sardone \& Devlin-Scherer, 2009). Over 20 years ago, the acceptance of using games in schools was unlikely by teachers, and many teachers were uninterested in integrating games into their teaching curriculum (Kearney, 2011).

The use of digital games in the classroom is becoming a more common phenomenon. Moreover, Ash indicates that the vast majority of teachers believe that using digital gaming has a lot of advantages, such as motivating low-performing students, monitoring student learning and providing constant feedback. Games make the learning easier for both students and teachers. Ash discovered that some teachers were working with games at least two days a week, while other teachers were using digital games every day in the classroom.

According to McCoy (2013), some teachers believe that constant use of digital technology "hampered their student's attention spans" and $70 \%$ of teachers thought digital gaming "hampered students' ability to write and communicate" face to face (p.3). So this is considered a big problem because they thought that digital games could distract "an easily distracted generation with short attention spans" and others said games "did more to distract students than to help them academically" (Foerde, Knowlton, \& Poldrack, 2006). Also, students cannot concentrate on learning new things when their brains are distracted and busy with another 
activity (Foerde et al., 2006). Therefore, a significant segment of teachers do not believe that using digital gaming in the classroom is a good idea or a useful tool.

The purpose of this qualitative study is to understand teachers' perspectives on using digital gaming among their students at Northern Illinois University in the state of Illinois. The importance of this study is that teachers are not knowledgeable enough about the value of using digital gaming in the classroom setting. So teachers cannot be expected to use digital games in their classroom without fully understanding the potential of using digital games. Thus, I will contribute to deliver a deeper understanding for teachers on the effectiveness of using digital gaming as a pedagogical tool in the teaching process.

\section{Literature Review}

\subsection{Introduction}

In the review of the literature many writers have written on teachers' attitudes toward using digital games in the field of teaching will be explored in this section to figure out the main reasons of why some teachers embrace games in the classroom and others not. The following literature review contain what the previous studies had done to support this study in three major areas: games as learning tools, teachers' views about the benefits of digital games, and students' motivation.

\subsection{Theoretical Framework \\ 2.2.1. Games as Learning Tools}

Digital gaming is a widespread activity in our society; more than 45 million homes have video-game consoles (Jinapriya, 2016). The term of digital game generally as an electronic game in the form of a computer PC, a console, or a cell phone that has animations on a video and computer screen. The digital game can be controlled by users following some rules and instruction to rich goals. So digital games can be used in an educational environment, to serve learning and teaching process these are known as "educational games" which are specifically designed for learning purposes. Teachers might use this medium as an adjunct in the class in order to: teach certain concepts, subjects, complex terms introduced during formal classes, give students the opportunity to apply their knowledge they learned, and practice some skills frequently until they become proficient. Frederick (2010) defined digital games as "a methodology that may hold special appeal to students who grew up in recent years with the explosion of digital games. And it is the term used to mean the use of computers to deliver an interactive, game like format of instruction to students"(p.3). In other words, games could be called "digital learning" which are learning devices that are built to support learning, help students to develop their skills such as communication, problem solving, creative thinking, and decisionmaking skills when learners are playing games (Noraddin, 2015).

In the past few years, there has been an increase in care to integrate digital games in schools to improve learning environments (Gros, 2007), as digital games stimulate active engagement in the learning process. Teachers must be utilizing digital gaming in the educational system because it has a significant role in the educational system and is more appropriate in today's school society. Also, when teachers provide games students focus more, become more engaged, and spend all their time playing electronic games. Notably, digital games contribute to build a high level of cognitive competency in students when they stay focused on specific tasks, makes students more active, increases motivation, and interaction with content/curriculum. In the future, digital games will change learning and teaching styles in the education system. Theoretically, digital games combines both learning theory and technology to make learning environments more useful. Therefore, the present study confirms one of the learning theories which is a constructivist approach to learning. According to Piaget (1980), philosophe of constructivism theory is a learning theory that states learners construct their own understanding and knowledge through their experiences and their abilities of interaction with the experience. When they are actively involved in the learning process it leads to increased motivation to obtain and apply knowledge (1980). Constructivism mostly supports active learning, or learning by doing (Sardone \& Devlin-Scherer, 2010). Bruner (1966) argues that in an active learning process allow learners to construct new ideas or concepts based on their current/past knowledge. From this standpoint, when teachers use games in the classroom to test students' knowledge and understanding by allowing them to apply and practice their knowledge that they learned previously during class by interacting with other students, it makes the learning environment more engaging. This way they can learn from the incorporation of their experiences, solve problems, increase self-efficiency and self- motivation, achieve required learning objectives in short amounts of time (Malone, 1982). There is a relationship between building knowledge and student learning through playing games when games are particularly designed based on the educational properties to achieve learning goals can be fitting way to improve learning (Papert, 1998). Moreover, games help to create a constructive learning environment that requires students to engage in different activities with other colleagues like discussions, conversations, and sharing ideas. So the concept of game-based learning is an effective tool in enhancing the learning process where students as players are able to interact with real world simulations to solve real problems, learn skills, knowledge, and values in an authentic environment. Squire (2002) believed that game-based learning can support and accelerate the learning process by continuing practice in which learners could reach the mastery level of knowledge. Game-based learning "can help 
students learning by practice and reflect on the errors being made when playing the game. Goal-oriented students are able to learn by exploring, based on their interest and curiosity which thereby is facilitating and enhancing their learning skills" (Gao \& Diao, 2014).

\subsection{Teachers' Views about the Benefits of Using Digital Games}

All over the world, some educational institutions have had many initiatives to encourage teachers to use digital games in school and university classrooms. However, teachers' views differ on the value of using digital games; some teachers are willing to use game. As Becker and Jacobsen (2005) reported, most of the teachers surveyed would be interested in trying to use games and simulations in class because traditional lecturing approaches make students become passive, just listening to the lesson without any interaction with the teacher, but games are more fun and interactive. The results indicated that these teachers had a strong belief that games are beneficial for learning. Similarly, a research study by Sardone and Devlin-Scherer (2009) stated that the purpose of the research is to examine teacher candidate perspectives towards integrating digital gaming design into contemporary curricula to support students' development of complex reasoning techniques. According to those teachers' responses, noting that games make it easier to understand difficult concepts, they allow for more engagement in the subject. In addition, some teachers stated that they felt that students learned more while playing. The findings indicated that training teachers to use classroom digital games improved their understanding, and students improved their concentration levels. Digital gaming provoked students to reason critically and develop elaborate problem-solving skills. Also, students developed multidimensional visual-spatial skills where they learn to read visual images as representations of threedimensional space. The article by Ray and Coulter (2010) explored whether the use of digital mini-games in a middle school classroom promoted student learning, and it sought to identify whether teachers believe that digital games enhance student learning in middle school. Most teachers agreed that their perceptions about digital mini-games improved after integrated in schools where it improves the social validity and this digital mini-games provided meaningful learning that positively motivated students.

However, teachers are reluctant to integrate digital games into teaching process because of a lack of resources (time and equipment), a lack of understanding of how to use games, and teachers having little time to learn. Becker (2007) identified that teachers can embrace digital game-oriented learning if they have a clear understanding of using games and an ability to employ games to promote teaching. Furthermore, other teachers indicated that they would be reluctant to use games because of the barrier of teachers lacking knowledge on how to use games. Essentially, the main reason for this lack was the deficiencies of their training to use games, and they were still adhering to traditional teaching methods (Becker \& Jacobsen, 2005). These are convincing evidence for non-acceptance of the idea of using games which must be taken into consideration by educators as well as policy makers to address this issues of employment digital games in the future.

\subsection{Students' Motivation}

During the 20th century, many questions come to educators' minds if the use of games in classrooms increase student learning and motivation. At this time, few empirical studies addressed the use of games in the classroom. Motivation is behavior or actions that cause people to take action toward their desires, needs, and goals such as having a desire to learn new knowledge and skills (Hong, Cheng, Hwang, Lee, \& Chang, 2009). According to Weibell (2011), students will be more motivated to learn when they realize that the new knowledge or skill will help them to achieve a goal in the present or future. Thus, a motivation is considered an important area to discuss to know that games could be the right tool to motivate students to learn. Basically, the majority of games are particularly designed to encourage a positive motivation for learners to learn. Flow theory is the best theory to understand motivation, which was originally defined by Csikszentmihalyi (1975) as "people are most happy when they are in a state of flow or "the zone" with a particular activity. The flow is an optimal state of intrinsic motivation, where a person is fully immersed in what he or she is doing" (p.33). In the other words, motivation itself includes two fundamental elements: "extrinsic motivation" and "intrinsic motivation" so "flow" to learn new knowledge without getting any reinforcement from teachers or anyone is considered an intrinsic motivation which could be defined in terms of self-motivated learning (Eggan \& Kauchak, 2004). "The intrinsic motivation of a person stems from his or her feelings of competency, personal development, and experience" (Nguyen, 2015). The other researchers' view that the enthusiasm of learners to play a game is an intrinsic motivation, when they engage in activities and practice previous experiences. But extrinsic motivation is receiving supports from outside sources, such as grades or rewards to reach certain goals. All these motivations are factors to push learners to learn. Hess and Gunter (2013) showed that students in both courses of a serious game-based and non-game based online American History course were intrinsically motivated through their positive social interactions and through the support of their innate psychological needs. Other study by Huang and Ke (2009) focused on the ability of games to motivate students to learn mathematics. This study discovered that students who use digital games integrated into math classroom activities had a significant improvement in motivation, and achievement compared with a traditional learning environment. Nguyen (2015) conducted study on university student's level in Vietnam to examine the impact of the web-based simulated game on students' intrinsic motivation 
who used games and compared to those who nonuse games. He cited that the students showed higher levels of intrinsic motivation and experienced a deeper level of learning when they learned through the game-based learning environment than other student who learned in a traditional school setting. As well as the result presented more positive facts where $51.7 \%$ of students extremely agreed that games were enjoyable, produced competence, and interest.

The findings of the literature review conducted above outline a number of benefits that digital games have on the learners and the learning process. It is clear that both the learner and the teacher stand to benefit if this strategy is implemented appropriately. However, I found that most of the empirical studies were focused on middle school students, which means there are few studies being conducted regarding teachers' opinions on the effectiveness of digital games on university students, so therefore, there is a deficiency of evidence regarding the use of digital games in university classrooms. Therefore, the gap of this study provoked me to attempt to fill the gap in literature by investigating teachers' views regarding the efficiency of using digital games in the classroom at Northern Illinois University.

Although I used a qualitative method for this study, I realized that the validity of the findings might be affected by some limitations. The first limitation of this study is the limitation on the time available. I was only able to conduct one interview with each participant. The interview time between 30 to 45 minutes is not enough to gain as much information as I would have liked. If the interview was longer, I may have been able to gather further data. The second limitation of this study is that I could not generalize the findings since they are based on the perceptions of only 5 teachers from Northern Illinois University in the state of Illinois. Utilizing participants through one university location may also limit the generalization of the findings.

\section{Methodology}

3.1. Description of the Site and Sample

The participants in the sample of this study were teachers at Northern Illinois University. There were five participants: three females and two males from different nationalities, specifically, Saudi Arabian, Caucasian /White, and Chinese. The sample age ranged from 30 to 45 years old. This study took place at Northern Illinois University in the state of Illinois. It is a public research university located in DeKalb. The main campus of NIU has 64 major buildings and seven colleges, including business, engineering, nursing, arts, education, and all teacher certification programs. The College of Education consists of six departments.

\subsection{Data Collection Procedures}

I used two different sources to collect data, one of which was semi-structured, one-on-one interviews (individual). The other resource was artifacts. Interviews included demographic information questions and some open-ended questions, which focused on teachers 'perspectives of using digital gaming in their classroom and the benefits of using digital gaming. All interviews were conducted once, and ranged in length from 30 to 45 minutes. I recorded these on audio-tape, and transcribed them afterward. Artifacts were a set of game pictures, they were collected from teachers after we completed the interview time. The participants immediately showed me games that they are using on their computer and I took a screen shot of the games. Other artifacts were also sent to my email by participants. The current study was guided by the following questions:

- What are the teachers' perspectives on using digital gaming in the classroom?

- What are teachers' perceptions of digital games as learning tools in classrooms?

- How do participants describe the use of digital games within their classroom?

- What do participants view as benefits of games?

\subsection{Data Analysis}

Once the interviews were over and data collection was accomplished, so it needs to be organized into a file folder to be ready for analyzing. After the data was transcribed, I started the phase of analyzing and interpreting the data that was derived from the participants by hand and I used a magenta colored marker to code data. In the data analysis process, I began reading interview transcripts many times then exploring any ideas, issues, or themes, that participants provided and I coded data in the margins of field notes to help me to narrow broader data into a few themes (Bogdan \& Biklen, 2007). As Emerson, Fretz, and Shaw (1995) suggested that to analyze field notes, I followed three procedures: I read the code intensively, I used open coding, and I wrote memos. During my reading, I divided codes into three categories of themes that came up during my reading of interview transcripts. These themes are views of learning benefits of gaming as related to relevant skills, potential reasons behind using educational games, and problem-solving skills. I started writing an analytic memo describing all ideas based on what I found from the interview transcripts and field notes in a meaningful way.

\section{Findings}

This resent research emphasized how teachers at different levels (secondary and college) view gaming as having benefits. These findings presented were reinforced by two kinds of resources. The first resource was 
conducting interviews and the second resource was artifacts given by participants in this study. Looking back through my formal interviews, I gained a range of answers and different views expressed by experienced teachers who used games in their classroom. I captured some insight and evidence about the effectiveness of the games provided by participants. In this section, the findings of this study showed three major themes based on teachers' responses: the potential reason behind using games, views of learning benefits of gaming as related to relevant skills, and problem solving skills.

\subsection{Views of Learning Benefits of Gaming as Related to Relevant Skills}

All of these teachers, except for one, agreed on the productive effect of digital games for students. According to the teachers' opinions, games are an attractive, useful tool for learning new skills like problem solving, and increasing intrinsic motivations for learners to keep them going without tirelessly trying to reach certain goals. Susan, a 30 year old teacher that I interviewed, indicated during our conversation that she uses games to teach how to use computers, how they work, and math course. She found games are a helpful way to engage students, and help them gain hands-on experience when they are using games to do their math assignments:

I should mention that they do Cool Math games that's a website also where are

kind of teaching them math. What they're do with their assignment they want to

go on Cool Math games. So I'm like that's fine because at least they are using the computer, but there's a lot of different ways to engage the students with games

because they like playing games at home and so an education games kind of help

students to keep connect with the content in a creative fun way

Also, Susan has seen the power of games on her $7^{\text {th }}, 8^{\text {th }}$, and $9^{\text {th }}$ graders. Through games, they learned some skills, such as thinking creatively, solving problems, and concentration. After playing games, students tried to apply problem solving techniques to real math simulation situations. They felt happiness because they like this way of learning and enjoy what they are doing, specifically with the Hour of code and Cool Math games. Another skill she mentioned was students were able to learn by themselves when they made a mistake and correct it until they reach the next level of the game. Through games, Susan's students gain self-directed learning skills and self-dependence skills. As well as games allowed her to keep her students busy all of the time and connect with the content. She said:

They all enjoy the games. I think it's beneficial to me because it keeps the students

busy and occupied. And they are learning and it's kind of self-direct learning. They

make a mistake they fix it and they're learning through the process of what they

doing wrong and how to fix it. I think games provide self-dependence skills where

the students can depend on themselves for the solving problems or figuring out

issues, looking up solutions for instance

Lastly, she concluded her conversation by encouraging teachers who believe that games have a negative impact to be open minded and at least try to use games. "I would suggest that to a lot of teachers to try to incorporate some sort of game into their curriculum to engage students in a different way."

Karl, another teacher I interviewed, supported the same positive perspective of Susan about the benefits of games for students. He reported that "using games increase students' engagement, motivate action, promote positive learning environments, are good for reinforcing content and knowledge of the learners, and teach students problem solving skills." However, he thinks that the over-use of not meaningful games might cause a negative influence on students. As he reported "a variety of games can have a negative effect if they are overused and if the games are poorly designed, they can be a problem."

Furthermore, Campbell, who has been using his own game for 5 years to teach a Mechanical Engineering class, shared his experience with me on how digital games were a powerful tool to facilitate teaching super intricate content, such as Computational Methods and Math courses. In these courses, he teaches students to perform calculations which are hard to do by hand. So the "Spumoni" game allowed him to make complex learning environments into more active and flexible environments by turning abstract things like complicated science concepts, physical principles, and theories of mathematics into hands-on experiences where students play to learn. Moreover, he offered similar assertions like Susan's view that games have a favorable effect on students. When they played games in his class, students became more engaged, creative, and motivated to figure out how the game works, and they gained unique skills like problem solving, self- directed learning, and computational thinking. He stated that:

I regularly teach a Computational Methods course, so in this Computational

Methods course, we teach students how to get a computer to perform calculations that are too difficult and messy to do by hand. I essentially turned that course into a video game. It's very complex. I thought could really benefit most from a game because students really got engaged in the games and I found that the games were really motivating so students spent a lot of time figuring out how to make things work. The student will be more creative and problem solving, and they go off and learn it by themselves 
Hana, a teacher from Saudi Arabia, was relying on games in teaching some subjects. Hana talked to me about the effectiveness of using games in enrichening knowledge for their players, whether they were teachers or students. Her perspective matched other teachers' opinions that digital games play a significant role in the implantation of self-confidence, encourage collaborative environments, share information with other classmates, develop all of communication, critical thinking, and technological skills when students play games. Hana directed my attention to a very important point about the advantages afforded by digital games: they contain texts, graphics, videos, and sounds, and all these elements are intended to aid students in understanding faster. She explained:

I used a few digital games in my classroom for kids at the age of and 10 years for teaching Arabic language alphabet, which contains a picture of words, letters, and sounds. I noticed that my students learn the pronunciation of the words correctly and quickly. I used the games that combine audio and visual emotions, and stimulate learners to use hearing and eyesight senses together

Despite all of these positive beliefs described by the teachers, there is one oppositional view by teacher Xaria. She had a different attitude from the teachers who had positive attitudes. She was against the idea of using games, especially with her PHD students, because she teaches seminar, theories, and research courses, and these courses require a high level of learning. However, teacher Xaria thought that games could work for young students and children. Also, she believes games are not a useful tool to teach a writing dissertation class:

I teach were seminar level and research level, so I can't find any a good games to teach because research by self-created, creation, creativity. As I mentioned before most of the teaching is creativity level like writing dissertation, I'm sure there's no games about dissertation class, and I don't think they are learning any kind of skills, and I don't think I will use any of those games in any graduate teaching. In the past when I was teaching game design class that I asked my students to play all different kinds of games but I don't see anyone being addicted to it but I have to say that they are all adult students

Moreover, teacher Xaria explicated that games are seen as benefits only when they help teach skills relevant to the course. She noted, "I don't find a lot of games that are helpful for addressing learning objectives. But after knowing the game I look at the learning objectives in my class. If the game can address the learning objective of course, I will use games." On the other hand, at the same time, she strongly believed that the games are fun and they provide opportunities to motivate learners to learn researching, reading, and practicing theories through playing games. She explained "I guess they are learning researching and reading theory, and the game helps them to understand the theory."

\subsection{Potential Reasons behind using Education Games}

It was clear that majority of the respondents often use games that are designed to serve educational purposes and to help them in issuing instructions to their students. When asked about potential reasons why they use these games, these respondents had different reasons. Teacher Campbell said, "my original reason is I thought it would be really fun to make material fun and I found that the games were really motivating so students spent a lot of time figuring out how to make things work." His main reason for using these games was to ensure that the students remain motivated even when it comes to handling complex concepts.

Hana, another teacher, was using games as activities to make sure students understand the content of the lesson correctly and to provide an opportunity for students to learn new skills, apply knowledge that was explained during class in hands-on experiences when they play games. She told me that "I use games during my class to test my students understanding and knowledge."

Karl explained why he uses games in the classroom. He said, "games are engaging and provide interactivity for the learners." As evident in his statement, he believed that by using these games, students get fully engaged in class work and they get to interact among themselves creating an environment where teamwork is cherished.

Susan stated that she uses digital games "to make things more like hands-on." She emphasized the argument that games make students engaged in their work. Also, Xaria mentioned the reason she uses games, she said, "motivation and also trying to basically give the students a chance to apply their knowledge." And she does not use games randomly but she choose games very carefully.

\subsection{Problem Solving Skill}

All teachers agreed that the most benefit of using games was push students to gain problem solving skills in order to have a deep understanding of the mathematics content. Thus, the discussion also showed that digital games made students improve their problem-solving skills. To win most of these games, the player is required to think critically and come up with the best solution. Therefore, it was necessary to determine if the respondents shared this view. In fact, it is evident that all the respondents believe that digital games help their students in improving problem solving skills. Karl said, "it really depends on the type and design of the game, students can learn problem-solving skills if the game is about problem solving." According to him, all that is 
necessary is to find the right games that focus on problem-solving. Using digital gaming is important in enhancing difficult subjects such as, Mathematics and Physics when most students often perceive to be complex. Also, games provided opportunities for students to exercise their problem-solving capabilities. As Campbell said that:

Primarily games are meant for educational purposes, particularly for engineer students that require them to apply fairly complicated mathematics and physics principles in order to solve problem. They do learn a few extra things, so in a traditional dynamics course for example student would solve problems out of a text book and there are sort of procedures one goes through. To a large degree those procedures are the same inside the game but there's a little extra thing you have to write those equations mathematically on a screen. It's more thinking about an algorithm, and how a mathematical rule would apply to solving a particular problem. Students will be more creative when solving problems.

Given that they use creativity to win the games, they are more likely to transfer that creativity to their class work. Teacher Xaria said, "digital gaming helps learners in understanding concepts of problem-solving theory." They can use the skills in their games in the academic and social life to solve different types of problems. They learned to think beyond the obvious to fix the puzzles in the game. This is what is needed of them in their social and academic lives. When they transfer such skills to their academic work, they realize that they can come up with unique solutions to some of the problems that they previously thought were complex. Also, students became very creative in solving problems in class, sometimes coming up with additional solutions beyond what the teacher offered. These are very important skills that will not only help these learners in their academic lives but also their social lives.

\section{Discussion and Conclusion}

In conclusion, the analysis of primary data has revealed that digital gaming is very important in improving the learning environment. The world is increasingly embracing emerging technologies and teachers believe that it is very important for the stakeholders in the education sector to adapt to these changes. Students, especially those who are in pre-college stage of their education, rarely find books to be interesting in the modern society. They spend most of their times playing games in their phones, computers, and other digital devices. It is possible to take advantage of this trend and make these games a learning platform. The main findings of this study discovered that most of the teachers who were interviewed seemed to have a positive attitude toward digital gaming and they think it that has a number of benefits that should not be ignored by the modern-day teachers if they want to have significant impact on the academic and social life of their students. Moreover, the results of this study revealed that teachers noted that using digital games increased students' engagement as well as improved students' skills, such as critical thinking, self- directed learning, technological skills, and self- motivation. Also, teachers believe that digital gaming helps students to improve their problem-solving skills. When they are involved in the games, they get to focus their full attention on winning. As such, they learn to focus their attention on one thing at a time. The engagement of students is also important because it makes them feel responsible. When their students play games, teachers feel that their students were in full control of the outcome of the game. This makes them know that in life, they are fully responsible for what happens to them. This is what it takes to ensure that students take full control of their academic lives. Teachers reaffirmed the claim that digital games promote creativity when solving problems, enhance students' engagement, and enable them to interact and work as teams to find solutions to their common problems.

A section of teachers has been skeptical towards digital games, questioning whether they can be used successfully in an academic setting. The study has revealed that indeed digital games have a bright future as a tool used at various stages of learning for different levels of students. Therefore, I argue that teachers and the educational policy makers should to embrace digital gaming as a learning tool. In the same manner, the prior studies indicated that some teachers' negative perceptions of using digital games were a significant barrier to implementation of the idea of integrating games into the classroom. The main reason teachers were reluctant to use games was the deficiencies of their training to use games, and a lack of knowledge about the benefits of games which must be addressed by educational policy. Also, Teachers must be trained very well before using games and schools should provide training programs led by people with expertise in using games.

For future research, since I did not find a lot of studies focusing on the effectiveness of using games for university students. I recommend other researchers to conduct empirical studies in this area and find convincing reasons for the lack of using games at this school stage. Another recommendation is to select target audiences from different school levels, such as middle school and graduate students instead of teachers. This would help to figure out the benefits of using games from students' perspectives as gamers.

\section{References}

Becker, K., \& Jacobsen, D., M. (2005). Games for learning: are schools ready for what's to come? Paper presented at the In DiGRA 2005 2nd International Conference, Changing Views:Worlds in Play'. DIGRA 2005. Vancouver, British Columbia, Canada. 
Becker, K. (2007). Digital game-based learning once removed: Teaching teachers. British Journal of Educational Technology, 38(3), 478-488. Available at: https://doi.org/10.1111/j.1467-8535.2007.00711.x.

Bogdan, R. C., \& Biklen, S. K. (2007). Qualitative research for education: An introduction to theories and methods. Boston: Pearson Education.

$\begin{array}{llllll}\text { Bruner, } & \text { J. } & \text { (1966). Constructivist } & \text { theory. } & \text { Retrieved }\end{array}$ http://www.instructionaldesign.org/theories/constructivist.html.

Csikszentmihalyi, M. (1975). Play and intrinsic rewards. Journal of Humanistic Psychology, 14(3), 41-63.

Eggan, P., \& Kauchak, D. (2004). Educational psychology windows on classrooms. Upper Saddle River, NJ: Pearson/Merrill Prentice Hall.

Emerson, R. M., Fretz, R. I., \& Shaw, L. L. (1995). Processing fieldnotes: Coding and memoing." Writing Ethnographic Field Notes (pp. 142-168). Chicago, IL: University of Chicago Press.

Foerde, K., Knowlton, B. J., \& Poldrack, R. A. (2006). Modulation of competing memory systems by distraction. proceedings of the National Academy of Sciences, 103(31), 11778-11783. Available at: https://doi.org/10.1073/pnas.0602659103.

Frederick, P. A. (2010). Using digital game-based learning to support vocabulary instruction for developmental reading students. Doctoral Dissertation. Nova Southeastern University, Florida, United State.

Gao, Y., \& Diao, Z. (2014). The feasibility of computer games in learning theory based subjects (Bachelor Thesis). University of Gävle, Gävle, Sweden.

Gros, B. (2007). Digital games in education: The design of games-based learning environments. Journal of Research on Technology in Education, 4O(1), 23-38. Available at: https://doi.org/10.1080/15391523.2007.10782494.

Hess, T., \& Gunter, G. (2013). Serious game-based online courses: Learning experiences and outcomes. British Journal of Educational Technology, 44(3), 372-385.

Hong, J. C., Cheng, C. L., Hwang, M. Y., Lee, C. K., \& Chang, H. Y. (2009). Assessing the educational values of digital games. Journal of Computer Assisted Learning, 25(5), 423-437.

Huang, K. H., \& Ke, C. J. (2009). Integrating computer games with mathematics instruction in elementary school-An analysis of motivation, achievement, and pupil-teacher interactions. World Academy of Science, Engineering and Technology, 60, 992-994.

Jinapriya, S. (2016). Knowledge development through constructionism game-based learning application. International Journal of Advance Research in Computer Science and Management Studies, 4(7), 204-208.

Kearney, C. (2011). Which knowledge and skills do teachers need to integrate games- based learning into their lesson.

Malone, T., W. (1982). Toward a theory of intrinsically motivating instruction. Cognitive Science, 5(4), 333-369.

McCoy, B. (2013). Digital distractions in the classroom: Student classroom use of digital devices for non-class related purposes: Retrieved from: https://www.researchgate.net/publication/257983603_Digital_Distractions_in_the_Classroom_Student_Classr oom_Use_of_Digital_Devices_for_Non-Class_Related_Purposes.

Nguyen, T. N. (2015). Motivational effect of web-based simulation game in teaching operations management. Journal of Education and Training Studies, 3(2), 9-15. Available at: https://doi.org/10.11114/jets.v3i2.565.

Noraddin, E. M. (2015). Three learning potentials in digital game: Perception of Malaysian University teachers. Journal of e-Learning and Knowledge Society, $11(2), 143-160$

Papert, S. (1998). Does easy do it? Children, games, and learning. Game Developer, 5(6), 87-88.

Piaget, J. (1980). Piaget's theory of cognitive development. Retrieved from; https://en.wikipedia.org/wiki/Piaget\%27s_theory_of_cognitive_development.

Ray, B., \& Coulter, G. A. (2010). Perceptions of the value of digital mini-games: Implications for middle school classrooms. Journal of Computing in Teacher Education, 26(3), 92-100.

Sardone, N. B., \& Devlin-Scherer, R. (2009). Teacher candidates' views of digital games as learning devices. Issues in Teacher Education, 18(2), 47-67.

Sardone, N. B., \& Devlin-Scherer, R. (2010). Teacher candidate responses to digital games: 21 st-century skills development. Journal of Research on Technology in Education, 42(4), 409-425. Available at: https://doi.org/10.1080/15391523.2010.10782558.

Squire, K. (2002). Cultural framing of computer/video games. Game Studies, 2(1), 1-13.

Weibell, C. J. (2011). Principles of earning: 7 principles to guide personalized, student-centered learning in the technologyenhanced, blended learning environment. Retrieved from: https://principlesoflearning.wordpress.com. 